\title{
Mermi Hareketinin Modellenmesinde Kullanılan Noble-Abel ve İdeal Gaz Denklemlerinin Akış Alanına Etkisinin Nümerik İncelenmesi
}

\author{
Seyda Özbektaş ${ }^{1}$, Bilal Sungur ${ }^{2 *}$ \\ ${ }^{1}$ Ondokuz Mayıs Üniversitesi, Mühendislik Fakültesi, Makine Mühendisliği Bölümü, Samsun, Türkiye, (ORCID: 0000-0001-7399-733X), \\ seyda.ozbektas@omu.edu.tr \\ 2* Samsun Üniversitesi, Mühendislik Fakültesi, Makine Mühendisliği Bölümü, Samsun, Türkiye (ORCID: 0000-0002-7320-1490), bilal.sungur@samsun.edu.tr
}

(1st International Conference on Applied Engineering and Natural Sciences ICAENS 2021, November 1-3, 2021)

(DOI: 10.31590/ejosat.1012916)

ATIF/REFERENCE: Özbektaş, S., Sungur, B. (2021). Mermi Hareketinin Modellenmesinde Kullanılan Noble-Abel ve İdeal Gaz Denklemlerinin Akış Alanına Etkisinin Nümerik İncelenmesi. Avrupa Bilim ve Teknoloji Dergisi, (28), 1093-1101.

$\ddot{O} \mathbf{z}$

Gelişen malzeme ve üretim teknolojileri ile birlikte silahlar küçülmeye başlamış ve bu problem büyük oranda çözülmüştür. Ancak silahlardan temel olarak elde edilmek istenen yüksek yıkım etkisidir. Bu durum günümüzde halen en önemli problemlerden birisi olan geri tepme kuvvetini de beraberinde getirmekte ve incelenmesi gereken bir konu olarak güncelliğini sürdürmektedir. Bir ateşli silahta geri tepme kuvveti barutun yanmasına bağlı olarak ortaya çıkan gazın basıncından kaynaklanır. Bu anlamda ateşli silah namlusunda hareket eden bir merminin etrafındaki akış alanının tahmin edilmesi gerekir ki bu oldukça karmaşık bir iştir. Karmaşıklıklar, türbülans, karmaşık yüzey geometrisi, hesaplama alanındaki zaman değişikliği, sıkıştırılabilirlik ve gaz denklemleri gibi çok sayıda faktörün varlığından kaynaklanmaktadır. Bu çalışma kapsamında yanma sonucu olan gazların davranışının modellenmesinde kullanılan Noble-Abel ve ideal gaz denklemlerinin, merminin akış alanı üzerindeki etkisi nümerik olarak incelenmiştir. Nümerik modellemede Fluent paket programı kullanılmıştır. Hesaplamalar iki boyutlu, kararsız, sıkıştırılabilir, eksenel simetrik şartlarda gerçekleştirilmiştir. Hesaplamalar sonucunda mermi etrafında oluşan basınç dağılımı, namlu ekseninden farklı konum boyunca çizilmiş ve bu konumlarda farklı zaman değerleri için basınç değerleri gösterilmiştir.

Anahtar Kelimeler: Nümerik modelleme, Dinamik analiz, Mermi, Namlu, Akış alanı.

\section{Numerical Investigation of the Effects of Noble-Abel and Ideal Gas Equations Used in the Modeling of Projectile Movement on the Flow Field}

\begin{abstract}
With the developing materials and manufacturing technologies, the guns started to get smaller and this problem was solved to a large extent. However, what is basically desired to be obtained from the guns is the high destruction effect. This situation brings with it the recoil force, which is still one of the most important problems today, and continues to be a topic that needs to be examined. In a gun, the recoil force is due to the pressure of the gas that occurs due to the combustion of gunpowder. In this sense, it is necessary to estimate the flow field around a projectile moving in a firearm barrel, which is a very complex phenomena. The complexities are due to the presence of a large number of factors, such as turbulence, complex surface geometry, time change in the computational domain, compressibility, and gas equations. In this study, the effect of Noble-Abel and ideal gas equations, which are used in modelling the behaviour of combustion gases, on the flow field of the projectile was investigated numerically. Fluent program was used in numerical modelling. Calculations were carried out in two-dimensional, transient, compressible, axisymmetric conditions. As a result of the calculations, the pressure distribution around the projectile was drawn along a position different from the barrel axis, and pressure values were shown for different time values at these positions.
\end{abstract}

Keywords: Numerical modelling, Dynamic analysis, Projectile, Barrel, Flow region. 


\section{Giriş}

Ateşli silahlar, bir yanıcı maddenin (genellikle barut) kimyasal enerjisinin kinetik enerjiye dönüştürüldüğü sistemlerdir. Namlu içerisinde yanan barut katı fazdan gaz fazına geçmekte ve bunun sonucunda oluşan gazlar namlu içerisindeki sıcaklığın ve basıncın artmasına neden olmaktadır. Basınç, merminin ilk hareketini başlatacak seviyeye ulaştığında mermi, namlu boyunca hızlanarak hareket etmektedir. Ateşli silahlarda merminin silah içindeki ve dışındaki hareketini ve bu hareket sonucunda hedef üzerinde meydana gelen etkiyi inceleyen bilim dalı balistik adıyla bilinir ve iç, dış ve terminal olmak üzere üçe ayrılır. Ateşleme başlangıcından merminin silah namlusunu terk edinceye kadar meydana gelen olayların tümü iç balistik alanıyla ilgiliyken, merminin namluyu terk ettikten hedefe ulaşıncaya kadar geçen zaman içinde meydana gelen olaylar diş balistik ile ilgilidir. Terminal balistikte ise mermilerin hedef üzerindeki yıkıcı etkileri incelenir.

Balistiklerin (özellikle iç ve dış) tam ölçekli deneysel testleri çok pahalı ve zordur. Bir namludan firlatılan bir merminin modellenmesi kararsızlıklar, sıkıştırılabilirlik ve zamana bağlılık gibi faktörler sebebiyle oldukça karmaşıtır. Merminin etrafındaki akış zamanla gelişecek ve değişecektir. Kararsız mermi aerodinamiğini deneysel olarak araştırmak ise çok kısa test süreleri gerektirmesi sebebiyle oldukça zordur. Teorik yaklaşımla çözüm ise, merminin aerodinamiğinde yer alan güçlü sıkıştırılabilirlik etkileriyle birlikte, kararsızlık ve üç boyutluluk gibi nedenlerden dolayı kolay değildir. Sonuç olarak, mermi hareketinin simülasyonu, erken bir tasarım aracı olarak oldukça arzu edilen bir durumdur. Günümüzde, Hesaplamalı Akışkanlar Dinamiği (HAD), son derece karmaşık kararsız, sıkıştırılabilir akış olaylarının çözümlemesinde kullanılan en etkili araştırma aracı olarak kabul edilmektedir. Literatürde mermi hareketinin akış alanı üzerindeki etkisiyle ilgili olarak teorik, sayısal ve deneysel birçok araştırma yapılmıştır (Bournot, Daniel, \& Cayzac, 2006; Carson \& Sahni, 2014; Cler, Chevaugeon, Shephard, Flaherty, \& Remacle, 2003; Danberg \& Nietubicz, 1992; Fansler \& Schmidt, 1978; X.-H. Jiang, Fan, \& Li, 2008; X. Jiang, Fan, \& Li, 2008; Z. Jiang, 2003; Le et al., 2004; Luo, Xu, \& Li, 2020; Mathur \& Dutton, 1996; Xavier, 2011; Zhuo, Feng, Wu, Liu, \& Ma, 2014). Jiang Z vd. (Z. Jiang, 2003; Z. Jiang, Huang, \& Takayama, 2004) akış alanının modellenmesinde şok dalgaları, jet akış etkileşimleri gibi dinamik süreçleri incelemişlerdir. Zhuo vd. (Zhuo et al., 2014) bir merminin namludan çıkışı ve serbest hareketini sayısal olarak araştırmışlardır. Yüksek hızlı hareket eden merminin modellenmesi için dinamik ağ yaklaşımı uygulamışlardır. Xavier (Xavier, 2011) çalışmasında 200 mm'lik bir namlu için $3450 \mathrm{~atm}$ basınç ve $2500 \mathrm{~K}$ sıcaklıktaki 1500 tane mermiyi ateşleyen 20 mm'lik bir ateşli silahın basınç ve ses dağılımının analizini gerçekleştirmiştir. Ayrıca mermi kütlesi, basıncı ve sıcaklığının akış alanına etkisini incelemiştir. Luo vd. (Luo et al., 2020), bir silahtan ortam havasına farklı geometriye sahip mermilerin firlatılması sırasında meydana gelen dinamik süreçlerin sayısal bir çalışmasını yapmışlardır. Carson vd. (Carson \& Sahni, 2014) çalışmalarında patlama sonucu namlu ağzının arkasında oluşan yüksek basınçları azaltmak amacıyla nümerik hesaplamalar gerçekleştirmişlerdir.

Silah iç balistiklerinin doğru bir şekilde modellenmesi, daha verimli silah ve sevk barutu tasarımı sağlar. İç balistik akış alanlarını simüle etmek için, bu tür modeller itici gazın termodinamik davranışının bir tanımını gerektirir. Literatürden de görüldüğü gibi çalışmaların büyük çoğunluğu baskılayıcı (susturucu) tasarımı ve bunların namlu etrafındaki akışa etkisi ile ilgilidir. Ancak gazların davranışının modellenmesinde kullanılan gaz denklemlerinin akışa etkisiyle ilgili çalışmalar sınırlı sayıdadır. $\mathrm{Bu}$ çalışmada, mermi hareketinin modellenmesinde kullanılan Noble-Abel ve ideal gaz denklemlerinin akış alanı üzerindeki etkisi nümerik olarak incelenmiştir. Nümerik hesaplamalarda Fluent paket programından yararlanılmıştır. Hesaplamalar iki boyutlu, kararsız, sıkıştırılabilir, eksenel simetrik şartlarda gerçekleştirilmiştir. Hesaplamalar sonucunda farklı konum ve zamanlara göre mermi etrafında oluşan basınç dağılımları incelenerek denklemler arasında karşılaştırmalar yapılmıştır.

\section{Materyal ve Metot}

Çalışma kapsamında literatürden (Xavier, 2011) alınan ve Noble-Abel gaz modeli kullanılarak modellenmiş $20 \mathrm{~mm}$ bir silahın basınç patlaması analizi ideal gaz modelleri kullanılarak analiz edilmiş ve elde edilen sonuçlar literatürdeki (Xavier, 2011) çalışmayla karşılaştırılmıştır. Mermi akışının modellenmesinde Fluent paket programı kullanılmıştır. Sınır koşulları literatürden alınan şartlarla aynı seçilmiş olup hesaplamalar iki boyutlu olarak gerçekleştirilmiştir. Kullanılan merminin ağırlığı 97.197 gram, çap1 $20 \mathrm{~mm}$, uzunluğu 36 mm'dir. Diğer taraftan namlu uzunluğu $200 \mathrm{~mm}$, yanma odas1 uzunluğu $100 \mathrm{~mm}$ 'dir. Oluşturulan geometrinin daha detaylı ölçülendirmesi Şekil 1'de gösterilmiştir.

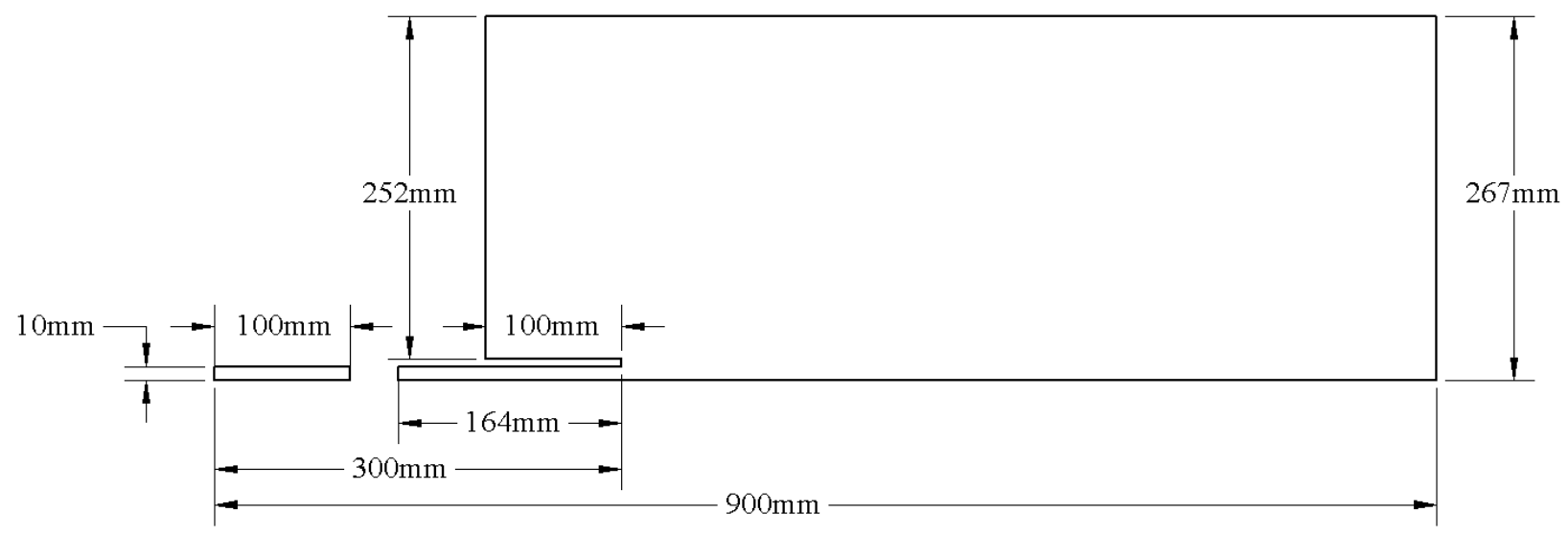

Şekil 1. Hesaplama bölgesi geometrik ölçüleri 
Oluşturulan modelde geometri, merminin hareket ettiği rijit bölge ve rijit bölgeyi çevreleyen dış ortam olmak üzere iki bölümden oluşmaktadır. Dış ortamın basıncı 1 atm, sıcaklığı 300 K'dir. Mermiye ilk hareketi verecek olan yanma odasının basınç ve sicaklık değerleri sirasıyla 3450 atm ve $2500 \mathrm{~K}$ olarak girilmiştir. Analizde kullanılan sınır koşulları Şekil 2'de verilmiştir. Fluent içinde çözücü tipi yoğunluğa-dayalı (DensityBased), zamana bağli, iki boyutlu eksenel simetrik
(Axisymmetric) olarak seçilmiştir. Türbülanslı akışı modellemek için Spalart-Allmaras türbülans modeli kullanılmıştır. Analizlerde kullanılan hava için yoğunluk ideal gaz olarak belirlenmiştir. Çözüm metodları bölümünde analiz için Implicit Formulation, akış tipi olarak Advection Upstream Splitting Method (AUSM) seçilmiştir. Zaman adımı büyüklüğü $10^{-7} \mathrm{~s}$ girilip, yakınsama kriteri $10^{-3}$ olana kadar iterasyonlar sürdürülmüştür.

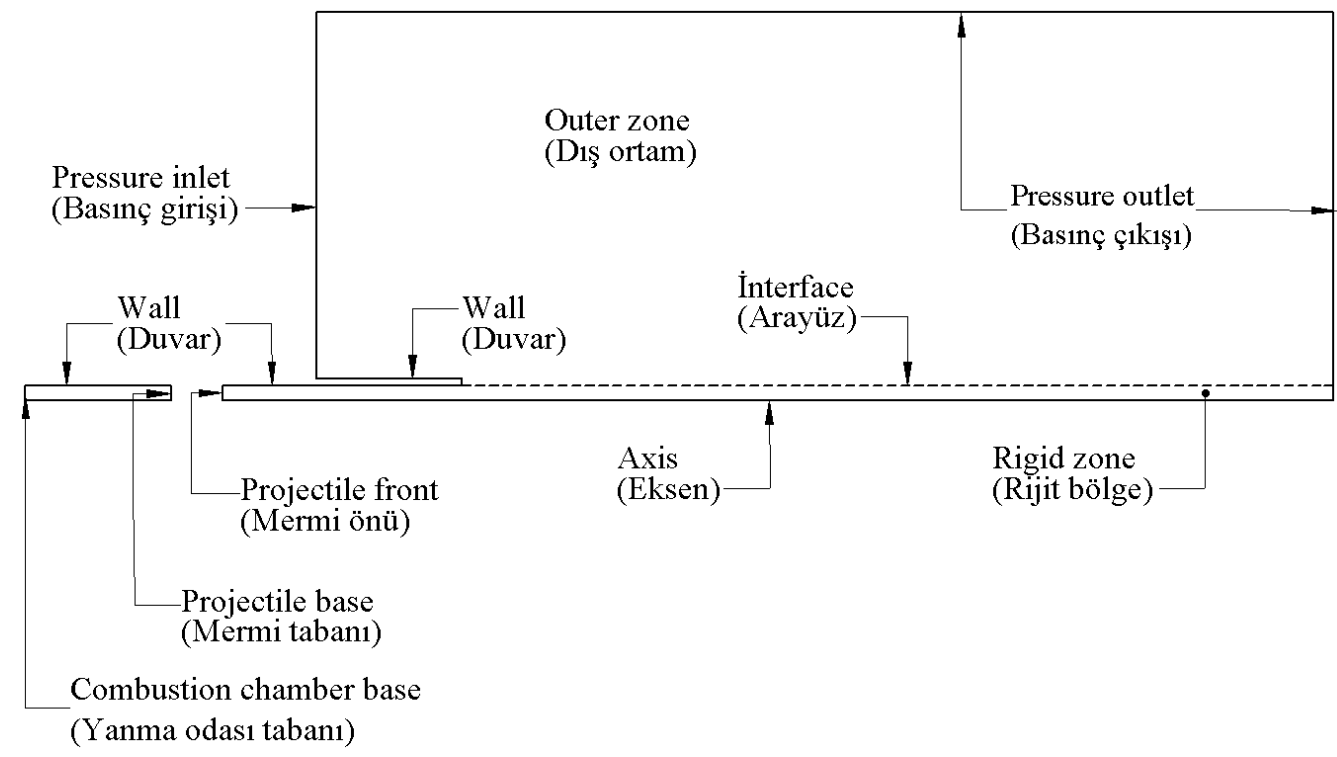

Şekil 2. Hesaplama bölgesi ve sınır şartları

Namlu boyunca hareket eden bir mermi modellenirken oluşturulan geometrideki sınır koşulları zamana bağlı olarak değişmektedir. $\mathrm{Bu}$ durumda kararsız akışı modellemek için hareketli sınıra sahip dinamik mesh yapısı kullanılmıştır. Merminin lineer bir yol izlemesi nedeniyle dinamik mesh işlemi için katmanlama (Layering) metodu seçilmiştir. Merminin serbestçe hareket edebilmesi için Altı Serbestlik Derecesi (SixDOF) aktif edilmiştir. Mermi ve hareket ettiği akışkan için katı cisim hareketi (Rigid Body) tanımlanmıştır. Yeni hücre katmanlarının ekleneceği yanma odası tabanı ve eski hücre katmanalarının çıkarılacağ̀ rijit bölge çıkışı, sabit bölge
(Stationary) olarak tanımlanmıştır. Mesh işlemi sırasında rijit bölgede dörtgensel (Quadrilateral), dış ortamda üçgensel (Triangle) elemanlar kullanılmıştır. İşlem süresinden tasarruf edebilmek amacıyla dış ortama rijit bölgeye kıyasla daha kaba mesh uygulanmıştır. Oluşturulan bu mesh yapısı 59910 noktadan ve 68681 eleman sayısından oluşmaktadır. İyi bir mesh yapısı için eleman kalitesinin (Element Quality) 1, çarpıklığın (Skewness) 0, ortogonal kalitenin (Orthogonal Quality) 1 değerlerine yakın olması istenir. Bu çalışmada ortalama eleman kalitesi, çarpıklık ve ortogonal kalite sırasıyla $0.98,0.02$ ve 0.98 elde edilmiştir. Ağ yapısının görünümü Şekil 3'te verilmiştir.

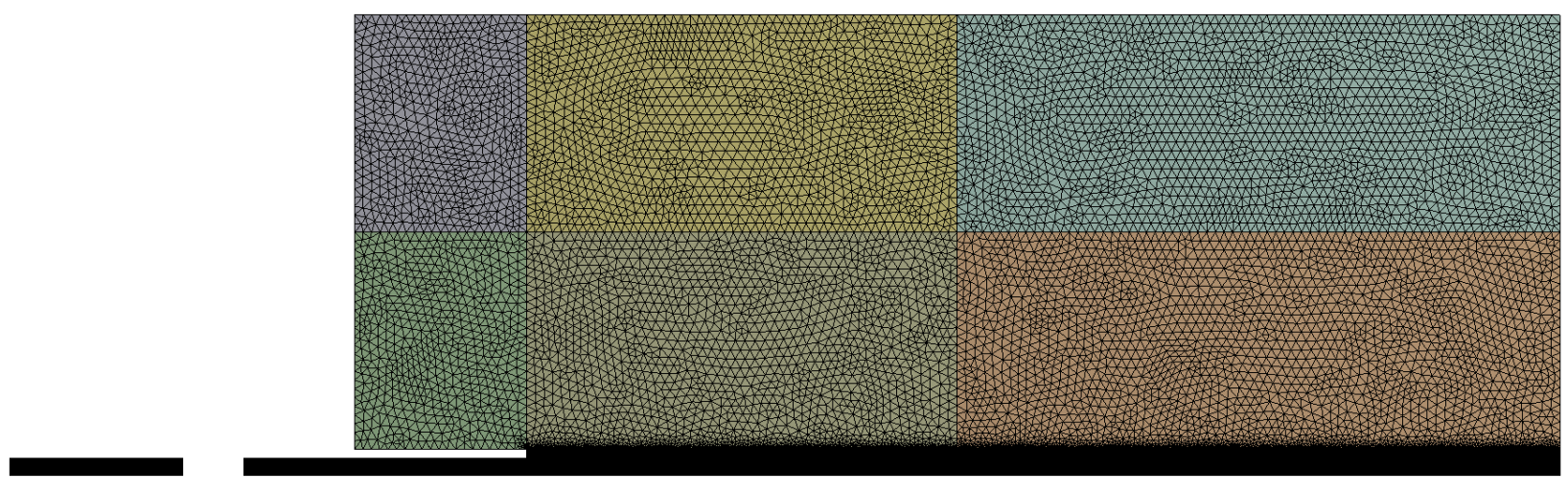

Şekil 3. Ağ yapısı genel görünümü 


\section{Araştırma Sonuçları ve Tartışma}

Silah ateşleme işleminde, merminin arkasında bulunan yüksek basınçlı itici gaz mermiyi ileri doğru hareket ettirir. Merminin önündeki hava, hareketli mermi tarafından sürekli olarak sıkıştırılır, bu da bir dizi sıkıştırma dalgasının oluşmasına neden olur. Sonraki her sıkıştırma dalgasının hızı, mermi ivmesi nedeniyle öncekinden daha hızlıdır. Farklı zamanlarda $(0.77 \mathrm{~ms}$, $0.86 \mathrm{~ms}, 0.97 \mathrm{~ms}, 1.1 \mathrm{~ms}$ ) merminin Noble-Abel ve ideal gaz modellerinden elde edilen basınç konturları Şekil 4'te verilmiştir. Şekilden de görüldüğü gibi akış alanının hacmi, şok dalgalarının namludan genişlemesi nedeniyle sürekli olarak artmaktadır. Merminin arkasındaki basınç değeri daha önce belirtildiği gibi 3450 atm'dir ve mermi namlunun aşağısına doğru hareket ettikçe bu değer azalmaktadır. Namlu içindeki konturun rengi kırmızı olsa da, aslında namlu iç kısmında basınç azalmakta ve ortamdaki basınç değeri artmaktadır. Noble-Abel denklemi kullanılarak yapılan çözümde merminin diğer denklemlere göre daha yavaş ilerlediği görülmektedir. Artan zamanla birlikte (özellikle $0.77 \mathrm{~ms}$ 'den sonra) ideal gaz denkleminden elde edilen görüntülerin Noble-Abel denkleminden elde edilen sonuçlara benzer olduğu görülmektedir. İdeal gaz denklemi kullanılarak elde edilen sonuçlarda akış alanının Noble-Abel durumuna kıyasla daha yüksek olmaktadır.

Noble-Abel ve ideal gaz modellerinden elde edilen zamana bağlı basınç değişimlerinin daha iyi yorumlanabilmesi ve kıyaslama yapılabilmesi amaciyla, $y=0.05 \mathrm{~m}$ ve $\mathrm{y}=0.1 \mathrm{~m}$ doğrusu üzerindeki üç farklı noktadan (Nokta 1: $\mathrm{x}=0.30 \mathrm{~m}$, Nokta 2: $\mathrm{x}=0.31 \mathrm{~m}$, Nokta $3: \mathrm{x}=0.32 \mathrm{~m}$ ) elde edilen basınç değerleri
5 'te verilmiştir.

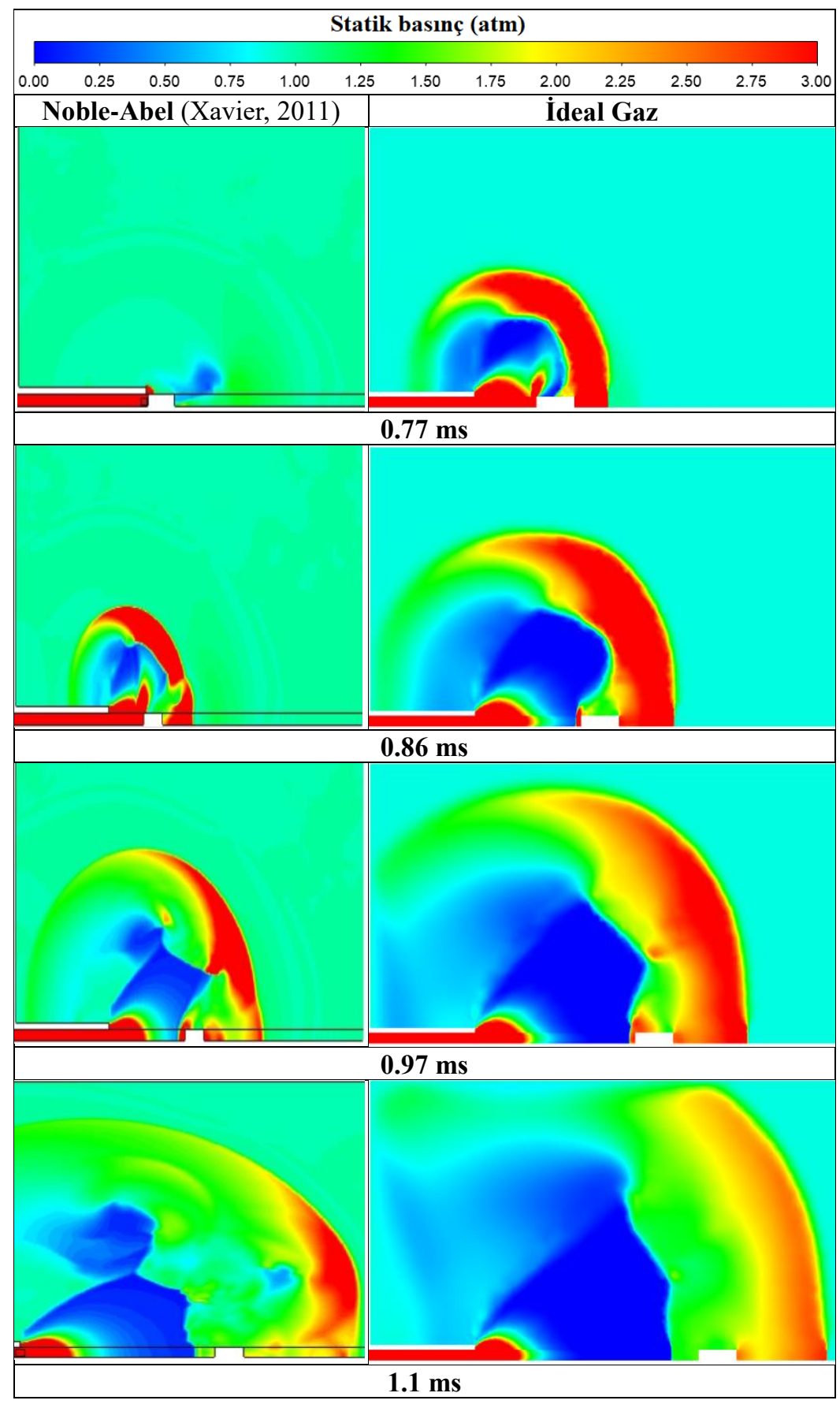

Şekil 4. Noble-Abel ve ideal gaz durumlarında elde edilen basınç konturları 
Şekil 5 incelendiğinde her iki denklemde benzer trendlerin oluştuğu görülmektedir. $\mathrm{y}=0.05 \mathrm{~m}$ pozisyonunda Noble-Abel denklemi ile yapılan çözümden elde edilen pik basınç değerinin ideal gaz durumuna kıyasla daha yüksek olduğu anlaşılmaktadır. Ayrıca $\mathrm{y}=0.05 \mathrm{~m}$ durumunda namluya daha yakın olan Nokta 1 pozisyonundaki basınç değerinin Nokta 3 pozisyonuna göre nispeten daha yüksek basınç değerinde olduğu belirlenmiştir. Ayrıca, $\mathrm{y}=0.1 \mathrm{~m}$ pozisyonunda namludan uzaklaştıkça (Nokta 1'den Nokta 3'e doğru) basınç değerleri arasında belirgin bir fark görülememektedir.
Şekil 6'da farklı zamanlarda $y=0.015$ doğrusu boyunca gaz modellerindeki konuma bağlı basınç değişimi verilmiştir. Şekil incelendiğinde $0.77 \mathrm{~ms}$ süresinde Noble-Abel gaz denklemi ile elde edilen sonuçlarla ideal gaz denklemi ile elde edilen sonuçlar arasında iyi bir uyum sağlanamadığı görülmektedir. Ancak artan zamanla birlikte Noble-Abel ve ideal gaz denklemi sonuçlarının birbirine yaklaştığ ve özellikle $0.87 \mathrm{~ms}$ süresinde oldukça benzer sonuçlar gerdikleri görülmektedir.

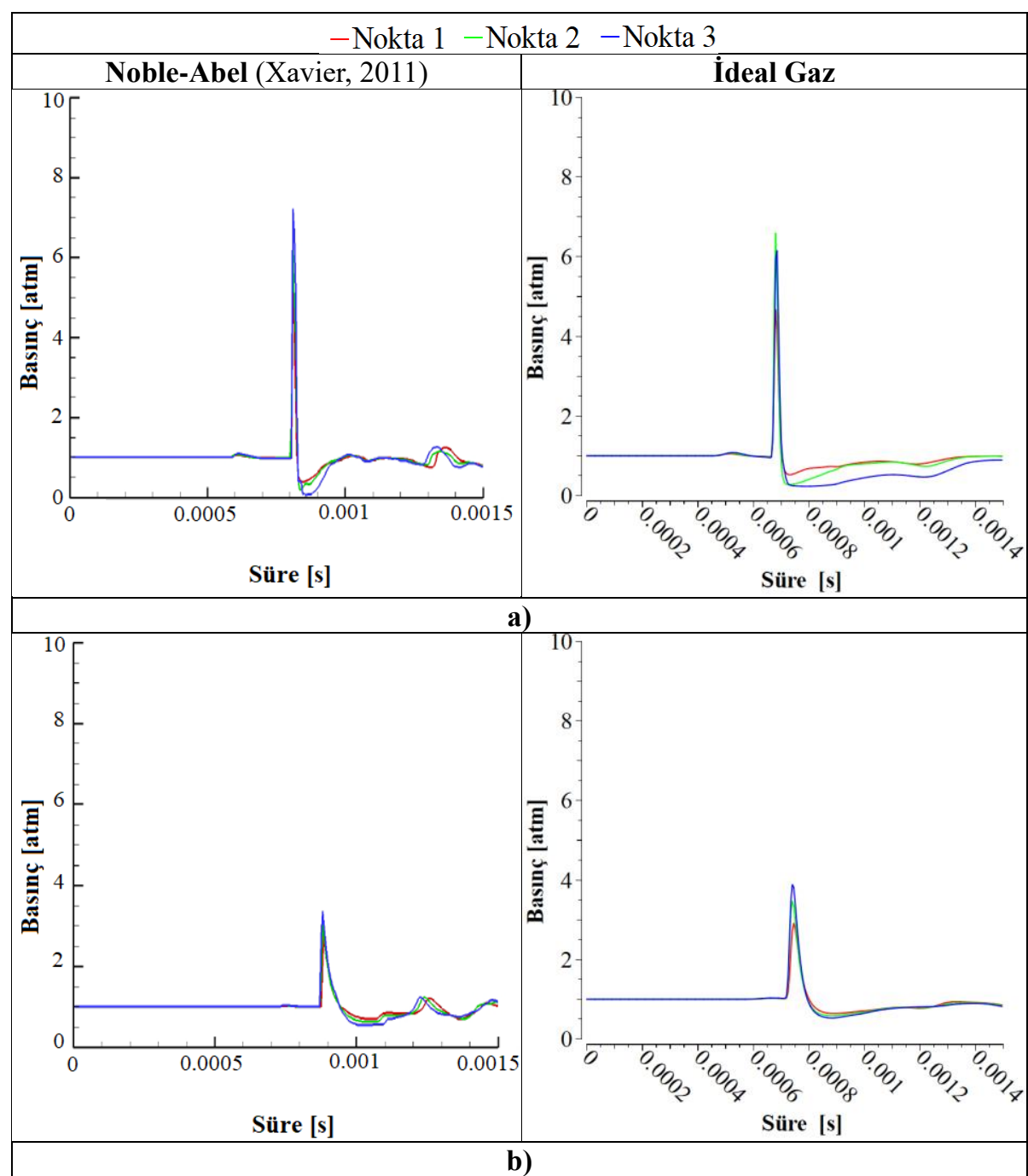

Şekil 5. a) $\mathrm{y}=0.05 \mathrm{~m}$ ve b) $\mathrm{y}=0.1 \mathrm{~m}$ doğrusu üzerindeki üç farklı nokta (Nokta $1: \mathrm{x}=0.30 \mathrm{~m}$, Nokta 2: $\mathrm{x}=0.31 \mathrm{~m}$, Nokta $3: \mathrm{x}=0.32 \mathrm{~m}$ ) için Noble-Abel ve ideal gaz modellerindeki zamana bağlı basınç değişimleri 


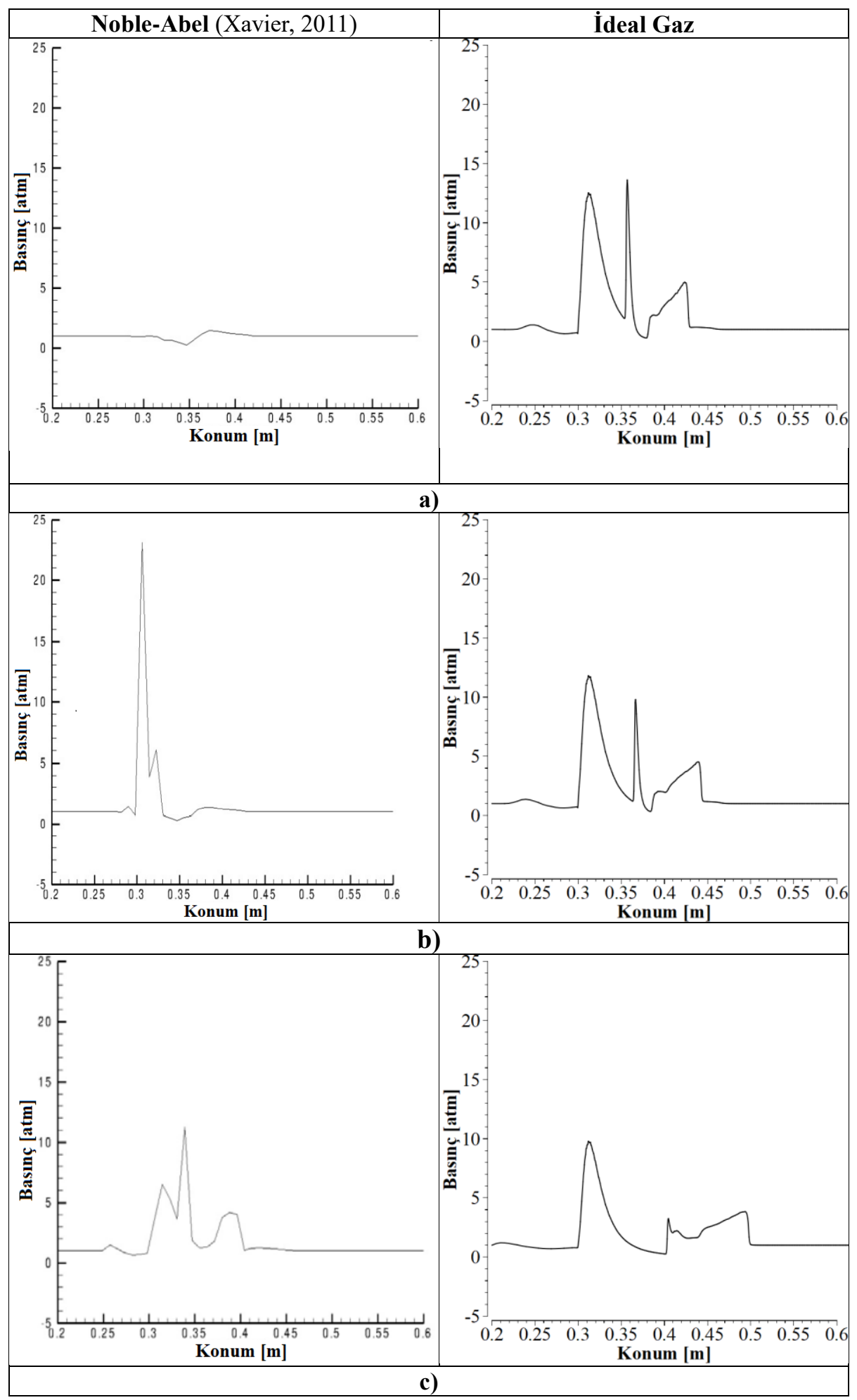

Şekil 6. a) $0.77 \mathrm{~ms}$, b) $0.79 \mathrm{~ms}$, c) $0.87 \mathrm{~ms}$ sürelerinde $\mathrm{y}=0.015$ doğrusu boyunca Noble-Abel ve ideal gaz modellerindeki konuma bağlı basınç değişimi

Şekil 7'de farklı zamanlarda merminin ideal gaz modeline göre elde edilen hız konturları verilmiştir. Artan zamanla birlikte akış alanı genişlemiş ancak maksimum hız değerleri düşmüştür.
Şekil 8'de ise farklı zamanlarda merminin ideal gaz modeline göre elde edilen sıcaklık konturları verilmiştir. Zaman ilerledikçe elde edilen pik sıcaklıklar düşmüştür. 
European Journal of Science and Technology

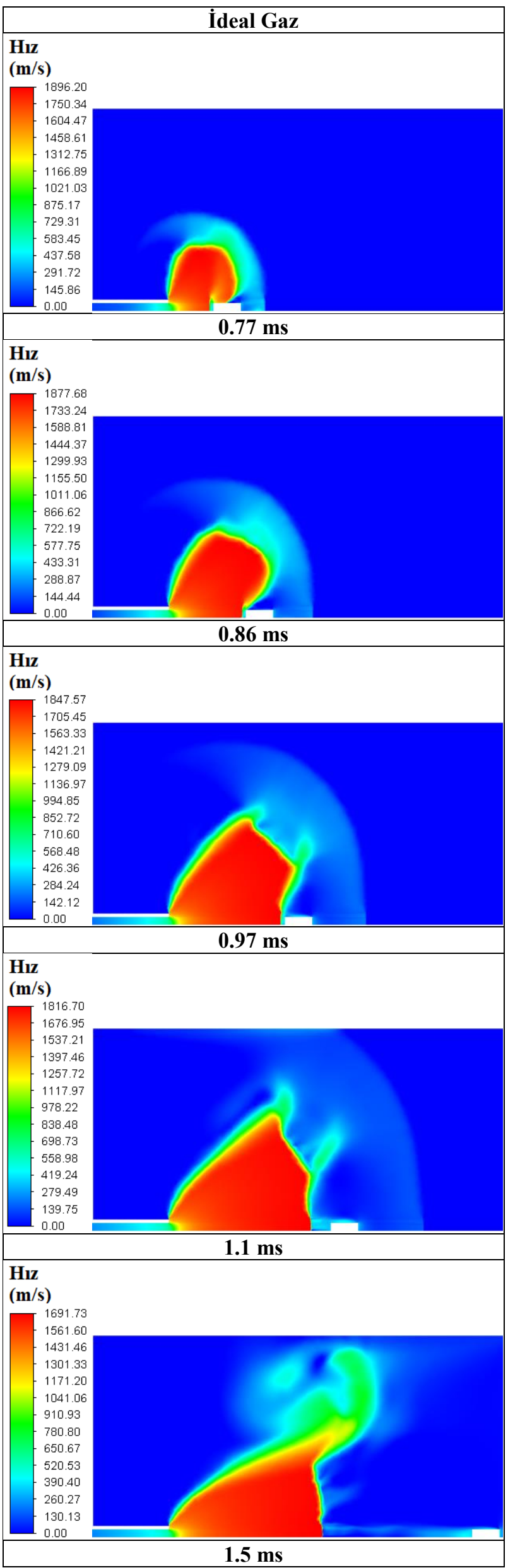

Şekil 7. Farklı zamanlarda merminin ideal gaz durumundaki hız konturları 
Avrupa Bilim ve Teknoloji Dergisi

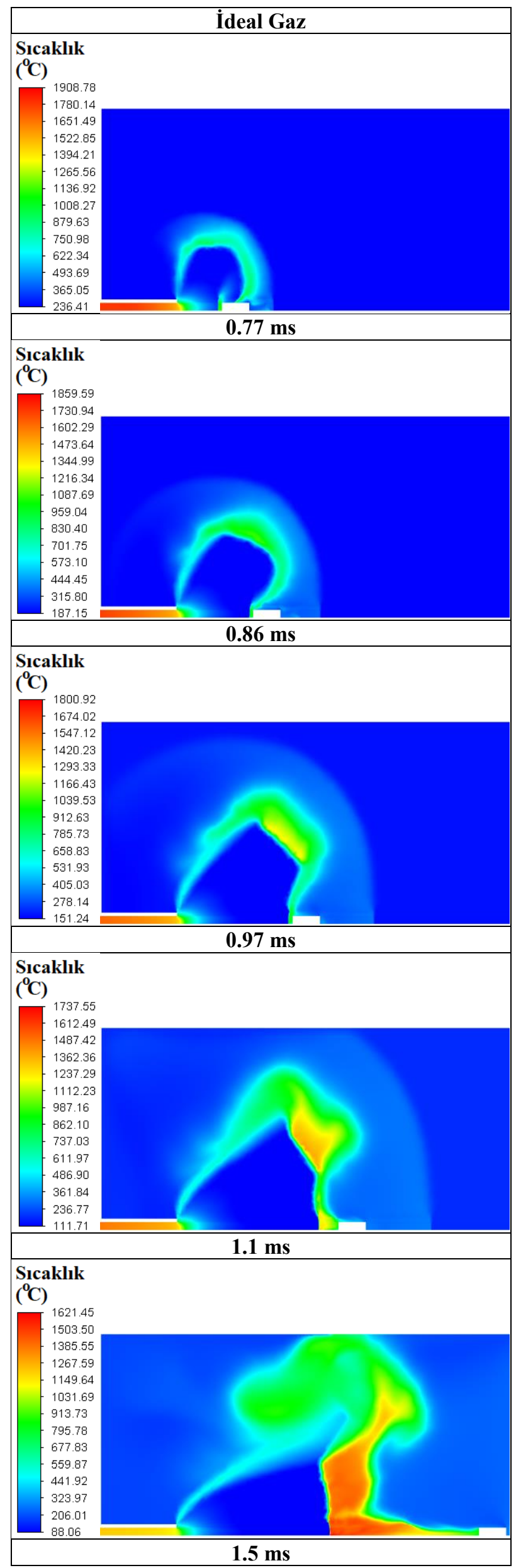

Şekil 8. Farklı zamanlarda merminin ideal gaz durumundaki sıcaklık konturları 


\section{Sonuç}

Ateşli silahlarda geri tepme kuvveti barutun yanmasına bağlı olarak ortaya çıkan gazın basıncından kaynaklanmaktadır. $\mathrm{Bu}$ anlamda ateşli silah namlusunda hareket eden bir merminin etrafındaki akış alanının tahmin edilmesi gerekir ki bu oldukça karmaşık bir iştir. Bu çalışma kapsamında yanma sonucu olan gazların davranışının modellenmesinde kullanılan Noble-Abel ve ideal gaz denklemlerinin, merminin akış alanı üzerindeki etkisi nümerik olarak incelenmiştir.

Sonuçlar değerlendirildiğinde:

- Akış alanının hacmi, şok dalgalarının namludan genişlemesi nedeniyle sürekli olarak artmıştır.

- Mermi namlunun aşağısına doğru hareket ettikçe namlu içi basınç değerinin azaldığı görülmüştür.

- Noble-Abel denklemi kullanılarak yapılan çözümde merminin ideal gaz denklemi ile yapılan çözüme göre daha yavaş ilerlediği belirlenmiştir.

- Artan zamanla birlikte ideal gaz denkleminden elde edilen görüntülerin Noble-Abel denkleminden elde edilen sonuçlara benzer olduğu tespit edilmiştir.

- İdeal gaz denklemi kullanılarak elde edilen sonuçlarda akış alanı, Noble-Abel durumuna kıyasla daha yüksek olmuştur.

- $y=0.05 \mathrm{~m}$ ve $\mathrm{y}=0.1 \mathrm{~m}$ doğrusu üzerindeki farklı noktalardan elde edilen basınç değerlerinin her iki denklemde benzer trendler oluşturduğu görülmüştür.

- $y=0.015$ doğrusu boyunca gaz modellerindeki konuma bağlı basınç değişimleri incelendiğinde $0.77 \mathrm{~ms}$ süresinde Noble-Abel gaz denklemi ile elde edilen sonuçlarla ideal gaz denklemi ile elde edilen sonuçlar arasında iyi bir uyum sağlanamadığ 1 tespit edilmiştir.

- Artan zamanla birlikte Noble-Abel ve ideal gaz denklemi sonuçlarının birbirine yaklaştığ süresinde oldukça benzer sonuçlar verdikleri görülmüştür.

- Farklı zamanlarda merminin ideal gaz modeline göre elde edilen hızlar değerlendirildiğinde, zaman artışıyla birlikte akış alanının genişlediği ve maksimum hız değerlerinin düştüğü görülmüştür. Zaman artışıyla birlikte elde edilen pik sıcaklıkların da düştüğü tespit edilmiştir.

İlerleyen dönemdeki çalışmalarda diğer gaz denklemlerinin ve türbülans modelleri gibi parametrelerin akış alanına etkileri incelenebilir.

\section{Kaynakça}

Bournot, H., Daniel, E., \& Cayzac, R. (2006). Improvements of the base bleed effect using reactive particles. International Journal of Thermal Sciences, 45(11), 1052-1065. https://doi.org/https://doi.org/10.1016/j.ijthermalsci.2006.0 1.018

Carson, R. A., \& Sahni, O. (2014). Numerical investigation of propellant leak methods in large-caliber cannons for blast overpressure attenuation. Shock Waves, 24(6), 625-638. https://doi.org/10.1007/s00193-014-0522-7

Cler, D., Chevaugeon, N., Shephard, M., Flaherty, J. E., \& Remacle, J.-F. (2003). CFD application to gun muzzle blast--a validation case study. 41st AIAA Aerospace Sciences Meeting and Exhibit.

Danberg, J. E., \& Nietubicz, C. J. (1992). Predicted flight performance of base-bleed projectiles. Journal of Spacecraft and Rockets, 29(3), 366-372. https://doi.org/10.2514/3.26360

Fansler, K. S., \& Schmidt, E. M. (1978). Trajectory perturbations of asymmetric fin-stabilized projectiles caused by muzzle blast. Journal of Spacecraft and Rockets, 15(1), 62-64. https://doi.org/10.2514/3.27998

Jiang, X.-H., Fan, B.-C., \& Li, H.-Z. (2008). Numerical investigation on the muzzle flow with dynamic mesh based on ALE equation. Jisuan Lixue Xuebao/Chinese Journal of Computational Mechanics, 25, 563-567.

Jiang, X., Fan, B., \& Li, H. (2008). Numerical investigations on dynamic process of muzzle flow. Applied Mathematics and Mechanics, 29, 351-360. https://doi.org/10.1007/s10483-008-0306-y

Jiang, Z. (2003). Wave dynamic processes induced by a supersonic projectile discharging from a shock tube. Physics of Fluids, 15(6), 1665-1675. https://doi.org/10.1063/1.1566752

Jiang, Z., Huang, Y., \& Takayama, K. (2004). Shocked flows induced by supersonic projectiles moving in tubes. Computers \& Fluids, 33(7), 953-966. https://doi.org/https://doi.org/10.1016/S00457930(03)00041-0

Le, G., Ma, D., Feng, Y., Shi, G., Zhu, Z., \& Song, X. (2004). Numerical simulation of muzzle blast flowfields of large caliber guns. 25, 19-22.

Luo, Y., Xu, D., \& Li, H. (2020). Analysis of the Dynamic Characteristics of the Muzzle Flow Field and Investigation of the Influence of Projectile Nose Shape. Applied Sciences, Vol. 10. https://doi.org/10.3390/app10041468

Mathur, T., \& Dutton, J. C. (1996). Base-Bleed Experiments with a Cylindrical Afterbody in Supersonic Flow. Journal of Spacecraft and Rockets, 33(1), 30-37. https://doi.org/10.2514/3.55703

Xavier, S. (2011). Numerical Analysis of Gun Barrel Pressure Blast Using Dynamic Mesh Adaption.

Zhuo, C., Feng, F., Wu, X., Liu, Q., \& Ma, H. (2014). Numerical simulation of the muzzle flows with base bleed projectile based on dynamic overlapped grids. Computers \& Fluids, 105 , 307-320. https://doi.org/https://doi.org/10.1016/j.compfluid.2014.08 .006 